\title{
A REGIONALIZAÇÃO DA SAÚDE: O CAMINHO PARA O SUS EM TODOS OS TERRITÓRIOS?
}

\author{
HEALTH REGIONALIZATION: A WAY FOR UNIFIED HEALTH SYSTEM (SUS) IN EVERY \\ TERRITORIES?
}

\author{
Michele Rocha El Kadri \\ Pesquisadora em Saúde Pública \\ Instituto Leônidas \& Maria Deane - Fiocruz Amazônia \\ michele.kadri@fiocruz.br
}

\begin{abstract}
RESUMO
Em 2016, a Secretaria Estadual de Saúde do Amazonas convidou instituições públicas de diversos setores para contribuir com suas experiências descentralizadas no debate da regionalização. Em comum, a extensão territorial, a dispersão populacional e condições de acessibilidade foram os desafios destacados. Na saúde a proposição de uma alternativa que responda adequadamente as demandas do território e que ao mesmo tempo esteja em conformidade com as orientações nacionais, levantaram o debate sobre exequibilidade da regionalização tal qual planejada normativamente em um estado de características tão singulares. Neste texto, elegemos dois pressupostos que orientam a regionalização para debater a capacidade desse arranjo em de fato responder as necessidades do Estado do Amazonas: organização de regiões para garantir economia de escala e a continuidade do espaço geográfico entre municípios limítrofes. Apresentamos algumas proposições que estão a ser debatidas localmente e que precisam estar contempladas dentro do arranjo nacional de modo a contemplar a realidade local, ultrapassando 0 instituído hegemonicamente. A regionalização como toda estratégia é pensada em pequena escala, contudo para que de fato alcance seus objetivos num estado como o Amazonas é preciso aumentar escala para reconhecer detalhes locais e assim adotar alternativas de fato regionais.
\end{abstract}

Palavras-chaves: Política pública em saúde. Modelos de atenção em saúde. Regionalização. Amazônia.

\begin{abstract}
In 2016, the Amazonas State Secretariat of Health invited public institutions from various sectors to share their decentralized experiences of regional planning. The vast territorial extension, population dispersion and accessibility conditions were the highlighted challenges for all. In public health, the proposition of an alternative that adequately responds to the characteristics of the place and at the same time complies with national guidelines has raised the debate on the feasibility of the regionalization of health policy as normatively planned in such a unique state. This paper highlighted two theorical assumptions raised with regionalization policy to debate the capacity of this arrangement to address the demand of the State of Amazonas: organization of regions to guarantee economy of scale and the continuity of geographic space between neighboring municipalities. We present some local propositions that need to be contemplated within the national arrangement in order to address the local reality, surpassing the hegemonic policy instituted. Regionalization of health, like every strategy, is small-scale, but in order to achieve its objectives in the States of Amazonas, it is necessary to scale up to recognize local details and thus adopt proper regional solutions.
\end{abstract}

Keywords: Public health policy. Models of health care. Regionalization of health. Amazônia

Recebido em: 13/10/2019

Aceito para publicação em: 11/11/2019

Artigo apresentado IX Simpósio Nacional de Geografia da Saúde, Blumenau, SC, 2019. 


\section{INTRODUÇÃO}

No Estado do Amazonas, o primeiro documento definindo as regiões de saúde foi elaborado no Plano Diretor da Regionalização em 2003 (AMAZONAS, 2003) conforme as orientações da NOAS 01/2002. O Pacto pela Saúde, nacionalmente estabelecido em 2006, para além da regionalização da assistência buscava a conformação de sistemas regionais para dar conta da integralidade do cuidado em saúde, instituindo para isso os Colegiados de Gestão Regional (CGR). O Amazonas foi o último estado da federação a aderir ao Pacto, o que ocorreu apenas em 2010, mas com o percentual de adesão municipal inferior a 50\% e sem criação de nenhum CGR até aquele ano (VIANA; LIMA; FERREIRA, 2010; LIMA et al., 2012a). Em 2012, já sob orientações do Decreto №. 7508/2011, os planos de ação para construção das Redes de Atenção à Saúde (RAS) nas regiões de saúde começaram a ser aprovados pela Comissão Intergestores Regionais (CIR). Desde então o Estado vem empreendendo esforço no sentido de planejar e executar as orientações nacionais no que concerne a Regionalização e implantação das Redes de Atenção à Saúde. O texto apresenta alguns argumentos que revelam pontos de tensão entre o instituído normativamente na organização e regulamentação do Sistema Único de Saúde e a realidade do território no qual a política deve ser implantada, no caso dessa análise o Estado do Amazonas.

Para fins de planejamento do uso territorial, a Constituição Estadual define nove zonas para desenvolvimento urbano-regional tomando por base a calha dos principais rios que cruzam o Estado (AMAZONAS, 2018), mesmo critério usado também para definição das atuais nove Regiões de Saúde desde 2011. Contudo, as secretarias municipais e mesmo pela própria Secretaria Estadual de Saúde tem identificado algumas inadequações desse corte, pois a definição das regiões de saúde não considera importantes situações geográficas: dispersão populacional no espaço; concentração dos serviços de média e alta complexidade (equipamentos e profissionais) na capital Manaus; dificuldade de fixação de profissionais de saúde nos municípios de menor porte, o que impossibilita prestação de diversos serviços e; principalmente, a grande extensão territorial do Estado e de seus municípios, o que impacta nas condições de acesso e transporte.

Em 2016, a Secretaria Estadual de Saúde do Amazonas promoveu uma série de encontros e oficinas para debater o processo de Regionalização no estado, convidando diversas instituições públicas que, assim como a própria Secretaria, devem estender suas ações numa área de $1.559 .146,876 \mathrm{~km}^{2}$. Instituições da área de ensino e pesquisa, como Universidades Estadual e Federal do Amazonas (UEA e UFAM), Instituto Federal (IFAM), Fundação Oswaldo Cruz (Fiocruz Amazônia), Instituto Brasileiro de Geografia e Estatística (IBGE), além da Superintendência da Zona Franca de Manaus (SUFRAMA), das três Forças Armadas e órgãos da Gestão Pública Estadual, como Secretaria de Planejamento e Secretaria de Educação, foram chamadas a contribuir no debate apresentando suas experiências de atuação descentralizada no Amazonas. Em outro momento, foram convidadas também as Secretarias Municipais de Saúde, Fundações Públicas de Saúde e Conselho de Secretários Municipais (Cosems-AM). A expectativa era que as experiências dessas instituições poderiam contribuir no debate sobre o processo de regionalização da saúde no estado. O ponto em comum de maior destaque é que a extensão territorial do Amazonas, a dispersão populacional e condições de acessibilidade (transporte e conectividade) são de fato os grandes desafios para ações setoriais públicas nesse lugar.

A construção de um consenso que responda adequadamente a tal contexto e que ao mesmo tempo esteja em conformidade com as orientações nacionais sobre a Regionalização, trouxeram inquietações sobre a exequibilidade de algumas dessas diretrizes num estado de características tão singulares, assim como a capacidade desse arranjo em de fato responder a demanda local. Este texto destacará dois pressupostos da regionalização da saúde, quais sejam a organização da Regiões de Saúde para garantir economia de escala e; a continuidade do espaço geográfico entre municípios limítrofes que compartilhariam infraestrutura de comunicação e transporte, apontando em como isso pode ser problemático dada a extensão territorial dos municípios amazonenses.

\section{REGIÕES DE SAÚDE E A ECONOMIA DE ESCALA}

As contribuições importadas do campo da economia influenciaram sobremaneira a proposta da construção de regiões de saúde como estratégia para prover integralidade do serviço de forma sustentável. Como instrumento de planejamento, a regionalização é uma estratégia para concentrar esforços, sobretudo políticos e econômicos, no desenvolvimento e ordenação dos espaços, 
envolvendo portanto o compartilhamento de poderes e recursos (LIMA et al., 2012b). O argumento é que a otimização de recursos depende de sua concentração, em especial os mais escassos, em determinados polos de desenvolvimento a partir dos quais os serviços e produtos seriam exportados e consumidos pela periferia.

Mendes (2011, p. 74) aponta que "a busca de escala é uma condição imprescindível para um sistema de atenção à saúde eficiente" sendo que os entes federativos deveriam definir responsabilidades e critérios para acesso e uso dos serviços de uma região. Economia de Escala é um conceito econômico para capacidade de uma empresa reduzir o custo médio de um determinado produto pela diluição dos custos fixos em um número maior de unidades produzidas. Considerando que os custos fixos são relativamente constantes, quanto maior o volume produzido, menor será o custo médio para produção de uma unidade, até um certo volume ótimo. No campo da saúde, se pensarmos que, independentemente do número de pacientes atendidos, uma unidade sanitária tem custos fixos para funcionamento (manutenção de equipamentos, pagamento de profissionais de saúde, estrutura física, etc.) quanto menos pessoas atender, maior será o custo unitário desse atendimento. Inversamente, quanto mais pessoas atendidas, menor será o custo médio. No entanto, a economia de escala só faz sentido quando existe demanda para atendimento, justificando assim a necessidade de concentração de serviços em certos pontos. Isso pode ser difícil, especialmente nos municípios do interior do estado, dadas as longas distâncias e condições de acesso entre o paciente e os centros onde o serviço estaria concentrado.

Excetuando-se a capital (que reúne toda a rede de alta e média complexidade nível 3) e mais quatro ou cinco municípios que por seu porte e desenvolvimento (até média complexidade nível 2) são aqueles que de fato teriam as condições para ser polos de referência com alguma densidade populacional, econômica, tecnológica e de influência cultural. Os demais municípios majoritariamente enquadram-se naquele grupo classificados por Lima et al. (2012b) que, por serem de pequeno porte, não agregam demanda suficiente para justificar a disposição de todos os níveis de atenção em saúde em seu território, além de apresentar limitada condição para assumir responsabilidade mais do que a atenção básica. $O$ pressuposto de que para que o sistema seja sustentável é necessário ter escala, apesar de real, neste caso pode não contemplar o princípio da justiça social. Mais da metade dos municípios do estado apresentam uma densidade demográfica inferior a 4,12 da Região Norte. Destaca-se que a capital concentra pouco mais da metade da população do estado (tabela 1). Como fazer então para prover assistência em lugares de imensa extensão territorial e de baixa densidade demográfica? As opções imediatas seriam deslocar as pessoas e adensar o contingente populacional em torno dos já superpopulosos centros urbanos (ou criar outros novos) ou ainda adequar a ação estatal para responder de modo mais adequado às necessidades de saúde das populações em seu território de origem.

Tabela 1: Classificação dos municípios por densidade populacional

\begin{tabular}{|c|c|}
\hline Densidade pop & Total de Municípios \\
\hline$<1 \mathrm{hab} / \mathrm{km}^{2}$ & 17 \\
\hline $1,00-1,99 \mathrm{hab} / \mathrm{km}^{2}$ & 17 \\
\hline $2,00-4,99 \mathrm{hab} / \mathrm{km}^{2}$ & 12 \\
\hline $5,00-9,99 \mathrm{hab} / \mathrm{km}^{2}$ & 9 \\
\hline $10,00-20,00 \mathrm{hab} / \mathrm{km}^{2}$ & 6 \\
\hline$>189,00 \mathrm{hab} / \mathrm{km}^{2}$ & 1 \\
\hline
\end{tabular}

Fonte: IBGE (2019)

Para exemplificar vamos tomar a questão da mamografia, principal exame para detecção precoce casos de câncer de mama e que deve ser anual a partir dos 40 anos. Segundo o Ministério da Saúde, o índice adequado deveria ser um aparelho de mamógrafo a cada 240 mil habitantes. Das nove regiões de saúde no Amazonas, apenas quatro concentram contingente acima de 200 mil habitantes ainda assim como alta dispersão populacional no território, a exceção de Manaus (tabela 2). As demais não atenderiam a tal critério populacional para ter o equipamento. Milhares de mulheres ficariam (e ficam!) desassistidas pela impossibilidade de deslocamento anual provavelmente à Manaus (que, por esse parâmetro, concentraria 9 dos 12 aparelhos que seriam alocados para o 
estado). Compreendendo a limitação desse critério assim como a importância de considerar o acesso das usuárias ao exame, o Ministério da Saúde (2017) propõe ainda o parâmetro de tempo de deslocamento de 60 minutos ou a distância máxima de 60 quilômetros. Ora, no espaço amazônico isso pode facilmente significar alocar equipamento para atender menos de 10 pessoas. No município de Barcelos, por exemplo, o cálculo per capita não se aplicaria, uma vez que teríamos pouco mais de 2.000 mulheres/ano elegíveis a fazer seguimento, tão pouco o critério minutos ou distância, visto que o município tem território de mais de 122 mil $\mathrm{km}^{2}$ e densidade demográfica de apenas $0,22 \mathrm{hab} / \mathrm{km}^{2}$ (IBGE, 2019). Ainda que houvesse um equipamento, seguramente ele seria subutilizado, pois mesmo que se considerássemos população dos municípios vizinhos, a distância que mulheres de outros municípios teriam que percorrer, comprometeria sua acessibilidade. Via de regra nem as sedes municipais tem tal distância entre si. Além disso, é imprescindível considerar as vias de acesso nessa análise. $\mathrm{Na}$ ausência de estradas, o transporte fluvial que segue o fluxo do rio produz um traçado muito diferente no mapa, variando ainda com a sazonalidade de enchente e vazante e com a potência do motor utilizado. Problemático definir um limite de distância quer seja 60, 120 ou $1000 \mathrm{~km}$ para acesso à saúde em tão extenso território.

Tabela 2: População por região de saúde

\begin{tabular}{|c|c|c|}
\hline Região de Saúde & $\begin{array}{c}\text { Estimativa população } \\
(2018)\end{array}$ & $\begin{array}{c}\text { Densidade } \\
\text { Populacional }\end{array}$ \\
\hline Triângulo & 125.164 & 0,95 \\
\hline Purus & 131.299 & 0,52 \\
\hline Juruá & 135.821 & 1,46 \\
\hline Médio Amazonas & 170.734 & 2,92 \\
\hline Madeira & 196.293 & 0,89 \\
\hline Baixo Amazonas & 247.196 & 3,61 \\
\hline Alto Solimões & 249.343 & 1,17 \\
\hline Negro e Solimões & 293.524 & 1,87 \\
\hline Manaus e entorno & 2.531 .237 & 6,93 \\
\hline
\end{tabular}

Fonte: IBGE (2019)

Aí está a tensão em se definir uma normatividade padrão, seja com perspectiva econômica ou pela do direito ao acesso quase sempre pensada a partir de centros urbanos populosos bem diferentes da realidade amazonense. Mendes (2011) ressalta que não se deve sacrificar o direito à saúde a critérios econômicos, contudo na prática, não são poucas as resistências que a gestão local enfrenta no diálogo com técnicos do ministério para fazer-lhes compreender as peculiaridades regionais. $\mathrm{Na}$ falta de conhecimento de um território, não raro sobram argumentos para localizá-lo apenas como lugar de ineficiência para alcance das metas nacionais.

Reconhecendo a singularidade do estado, a Secretaria Estadual de Saúde mantém (direta ou indiretamente) unidades hospitalares em todos os 62 municípios do Estado com algum nível de densidade tecnológica assistencial (média complexidade nível 1 com maternidade em todos e nível 2 em alguns municípios). A exceção de um hospital universitário e de uma maternidade municipal na capital, além de 2 hospitais de guarnição sob gestão do exército em municípios de fronteira, toda a rede hospitalar pública é de gestão estadual. Isso certamente tem impacto na capacidade de planejamento e atuação estratégica dessa Secretaria, uma vez que recursos financeiros, humanos e técnicos são comprometidos na gestão direta da rede assistencial.

É preciso ainda considerar a questão da qualidade dos serviços que tem relação estreita com o volume de atendimentos (escala) realizados. Isso quer dizer que "serviços de saúde ofertados em maior volume são mais prováveis de apresentar melhor qualidade... [e portanto] deve-se analisar o tamanho dos serviços e o volume de suas operações como uma proxy de qualidade" (MENDES, 2011, p. 73). Quanto mais um serviço oferta um procedimento, melhor será sua organização interna em ofertá-lo, incluindo a prática profissional daqueles que o executa. Ainda que imaginássemos um mundo ideal de fartura de recursos e a oferta de serviço estivesse disponível em todos os níveis para todos os municípios, a baixa demanda em si poderia comprometer a qualidade do serviço prestado. 
Nesse sentido, parece razoável pensar uma racionalidade inovadora e soluções alternativas para assistência nesse contexto que é tão distinto dos centros urbanos e com uma "ruralidade" também distinta de outras zonas rurais do país. Isso requer um planejamento que supere o pensamento hegemônico que no campo da saúde não raro tem produzido análises que localizam a região como lugar da doença, da incipiência de processos organizativos, do vazio e da vulnerabilidade, desconsiderando os processos naturais e históricos que marcam a construção do SUS nesse território.

\section{EXTENSÃO TERRITORIAL E CONDIÇÕES DE TRANSPORTE NO ESTADO}

A questão do acesso é um tema muito discutido sob diversos enfoques, em especial no campo da avalição de serviços. $O$ aspecto que nos interessa discutir aqui circunscreve-se ao acesso geográfico como relação entre a localização dos usuários (proveniência) e dos serviços (destino), considerando ainda tempo de locomoção, custos e disponibilidade de transporte (SANTANA, 2014).

A expansão da Atenção Básica a partir da implantação do modelo Estratégia de Saúde da Família representou avanços importantes na ampliação do acesso à saúde (VICTORA et al., 2011), e no estado foi um marco importante na assistência nos municípios do interior (SCHWEICKARDT; MARTINS, 2017). Apesar de sofrer com a irregularidade da oferta de médicos para compor as equipes, atualmente $68,8 \%$ da população do Amazonas é assistida por uma equipe de saúde da família, sendo que em mais da metade dos municípios a cobertura é superior a $90 \%$ (MINISTÉRIO DA SAÚDE, 2018). Contudo, o maior constrangimento permanece sendo acesso à atenção especializada e de urgência.

Em primeiro lugar é preciso compreender as distâncias e vias de acesso no Estado do Amazonas. Aqui sim o fator econômico se impõe fortemente. A extensão territorial amazonense por si só poderia, mas de fato não representa um atrativo para operações aéreas, devido alto custo pela falta de infraestrutura adequada. A demanda certamente existe tanto de passageiros quanto de cargas. Além de Manaus, que é o $3^{\circ}$ aeroporto brasileiro em volume de carga e $18^{\circ}$ em passageiro, o estado conta com nove aeroportos que recebem voos de passageiros comerciais regulares nos municípios do interior. Alguns poucos outros municípios contam com pista para receber aviões de pequeno porte (táxi aéreo). Se considerarmos que a oferta de transporte precede o desenvolvimento de atividades econômicas, desenvolver essa via de acesso a um custo razoável, poderia favorecer o fluxo de passageiros e cargas para o interior do estado.

Já o desenvolvimento de malha terrestre é extremamente controverso e opõem grupos ambientalistas e grupos que defendem sua abertura para vencer o isolamento. Além da questão ambiental, sua eficiência tende a ser proporcionalmente menor quanto maior forem as distâncias a ser percorridas, numa relação que equaciona tempo $X$ volume de material/passageiros transportados (JESUS, 2014). Exemplo emblemático é a Rodovia Transamazônica que mesmo nos trechos de boa conservação é muito subutilizada por percorrer distâncias extraordinariamente longas entre um centro urbano e outro.

Dada a vocação natural do estado, a via fluvial tem sido desde sempre aquela que equilibra custos e uso menos degradante do meio natural. O maior volume de carga transportado a menor custo de operação, compensaria parte das perdas com elevado tempo de deslocamento. A Região Hidrográfica Amazônica forma uma rede de rios de $50.000 \mathrm{~km}$ de trechos navegáveis estendendo-se em sete estados do país, sendo que desse total $40 \%$ concentra-se no Estado do Amazonas (MINISTÉRIO DO MEIO AMBIENTE, 2006). Estima-se uma demanda em 2017 de mais de 1,6 milhão de passageiros em mais de 73 linhas estaduais atendendo a todos os municípios (BRASIL, 2018). Ainda assim, a precariedade na sinalização, acomodações portuárias, equipamento de auxílio à navegação não permitem que os trechos navegáveis sejam de fato qualificados como hidrovias (MOURA; FROTA, 2016; KADRI; LIMA; SCHWEICKARDT, 2017). Apesar da sazonalidade de vazante e enchente, além do próprio Rio Solimões-Amazonas, seus principais afluentes em ambas as margens têm condições de navegabilidade para embarcações de grande porte perenemente no curso principal do rio.

Para exemplificar a disparidade das escalas a quais as diretrizes nacionais da regionalização pretendem responder, como equiparar em extensão o município de Barcelos (AM) em sua área de 122 mil km² e o município do Rio de Janeiro com $1.200 \mathrm{~km}^{2}$ ? Em termos de população, como 
organizar um sistema para atender 30 mil habitantes neste município do Amazonas e atender mais que o dobro disso concentrado num único espaço urbano como favela da Rocinha na capital fluminense? Não se trata simplesmente da diferença de números, mas sim do uso e ocupação muito distinto dos respectivos territórios. Dessa forma, parece razoável considerar que as ações de saúde devam ser planejadas e avaliadas de modo diferente nesses dois cenários, o que implica inevitavelmente distribuição desigual de recursos. A regionalização como estratégia para assegurar acesso universal deve ser pensada na pequena escala, contudo a regionalização como norma que orienta as ações cotidianas, precisa considerar uma escala maior no planejamento e organização dos serviços de saúde, de modo que a particularidade dos lugares se torne visíveis. Este é o desafio de ter um sistema universal, mas com uma organização local. A desconsideração da questão da escala para análise, planejamento e avaliação do SUS nos lugares, tem produzido distorções abissais e injustas, que pelo discurso do "é muito complexo" tem justificado a ausência de repostas adequadas. Nos círculos locais de discussão, embora ainda careça de parâmetros capazes de justificar uma estratégia alternativa para o Amazonas, considera-se a possibilidade de propor um outro desenho organizativo para assistência a partir dos fluxos e mobilidade dos territórios mais do que em pontos fixos e imóveis. Essas alternativas partem do entendimento que o rio historicamente tem sido o elemento fundamental de conexão entre as pessoas e os lugares. Nesse contexto, a organização da vida e o uso que se faz do território é distinto do uso de territórios que se conectam por vias terrestres.

Figura 1: Distribuição da população na Amazônia Legal (2010)*

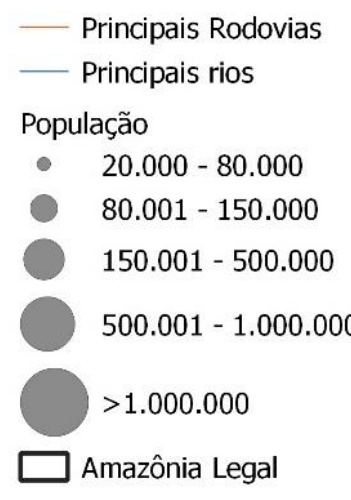

* População municípios com mais 20 mil habitantes. Demais não representados Elaboração: Michele R. El Kadri Base SIRGAS 2000
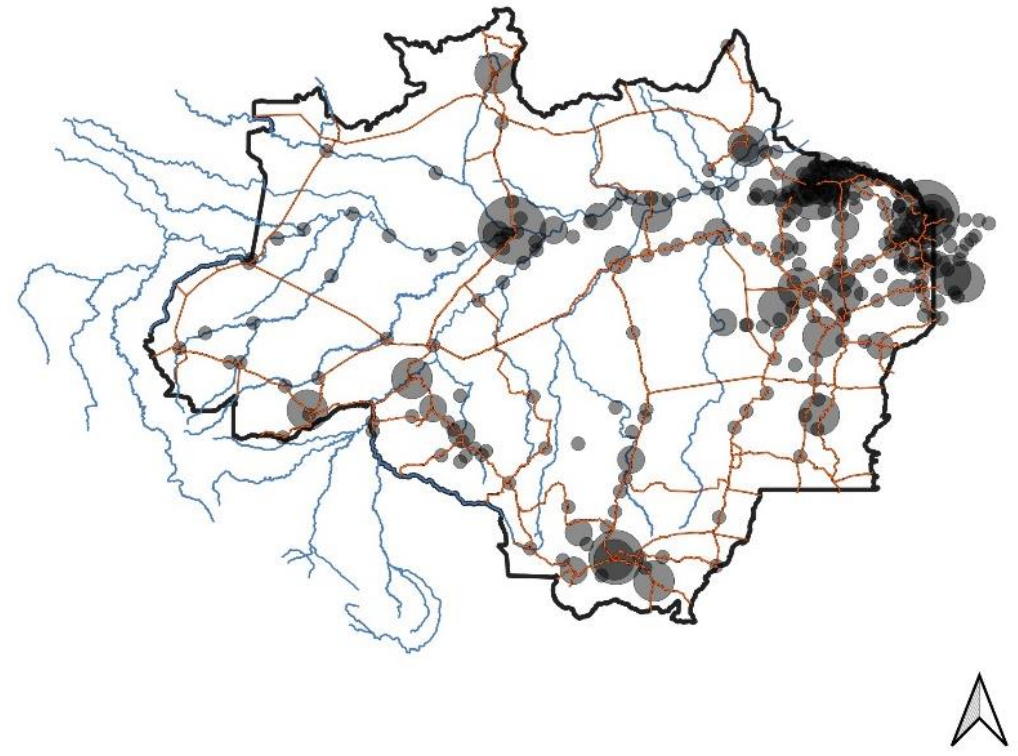

$0 \quad 250500 \mathrm{~km}$

Além de ter contexto diferente do resto do país, a região tem diferenças marcantes entre si. A figura 1 mostra um padrão diferenciado de ocupação na Amazônia Oriental (ao longo das estradas e de maior concentração demográfica) e na Amazônia Ocidental (ao longo dos rios e com menor concentração demográfica). No Amazonas, o rio tem sido historicamente importante na ordenação do espaço, o que reforça a importância do ciclo de enchente e vazante dos rios e a implicação do fenômeno sazonalidade no uso que se faz do território. Essa sazonalidade interfere na moradia, alimentação, custo de vida e de produção, deslocamento no espaço, acesso a serviços incluindo os de saúde, mudanças nas atividades produtivas e até mesmo percepção diferenciada da passagem do tempo. 


\section{ALGUMAS ALTERNATIVAS}

Diante desse cenário, no campo da saúde parece razoável pensar em estratégias diferenciadas para garantir integralidade do serviço além da Atenção Básica, embora se reconheça a necessidade de uma discussão mais ampla sobre o modelo de desenvolvimento para o estado a longo prazo. Nosso entendimento é que as estratégias de provimento do serviço de atenção especializada e do serviço de urgência devem ser distintas.

Como já vimos, critérios econômicos e/ou geométricos têm limitada capacidade para responder adequadamente às demandas do Amazonas. $\mathrm{Na}$ atenção especializada, um serviço itinerante com equipes que se desloquem periódica e regularmente ao menos às sedes municipais poderia ser uma estratégia alternativa para melhorar o acesso sem que usuários tenham que arcar com custos individualmente para transporte. Seguindo os bons resultados das Unidades Básicas de Saúde Fluviais nos municípios que desse equipamento dispõe, a ideia que vem sendo discutida é a possibilidade de policlínicas fluviais com os serviços mais demandados de especialidades como ginecologia-obstétrica, pediatria, ortopedia e ainda cardiologia - considerando o perfil demográfico e epidemiológico de uma população jovem e com elevada fecundidade. Demais especialidades de menor demanda e/ou cuidado com menor número de seguimentos teriam agendas mais espaçadas. Cabe destacar que há um limite para tal proposta, uma vez que há serviços que necessariamente dependem de objetos técnicos fixos, como por exemplo rede elétrica estável para funcionamento de alguns equipamentos, o que significa que nem todos os serviços poderiam "navegar no banzeiro". Outras especialidades como psiquiatria, oftalmologia, cirurgias eletivas teriam agendas próprias com visitas regulares dentro unidades hospitalares. Embora estratégia de levar serviços mais próximos a população pareça óbvia nesse cenário, de fato isso não tem sido uma prática institucionalizada e executada com frequência necessária, a não ser no modelo campanhista. Uma estreita relação com equipes de atenção básica é fundamental para coordenação dessa estratégia. Para gestão local é claro que essa não uma solução definitiva, mas por certo é viável e com resultado imediato na melhoria do acesso. Ainda, o recurso da telemedicina expandido em quantidade (mais tutores) e qualidade (infraestrutura de conectividade) são recursos bem úteis e eficazes na orientação das equipes de atenção básica no dia-a-dia.

Quanto ao serviço de urgência, considerando a extensão territorial e condições de acesso, de fato parece não haver alternativa melhor do que transporte aéreo sanitário, dado que nas atuais condições o deslocamento rápido sempre se fará necessário para um centro urbano. Contudo, descentralizar serviço de alta complexidade para 1 ou 2 novos centros de atendimento além de Manaus seria medida que beneficiaria toda a rede de saúde no estado. Hoje o custo médio de remoção de um paciente do interior para Manaus é de $R \$ 21$ mil valor frequentemente custeado pelos municípios. A Secretaria Estadual de Saúde recebe média de 8 solicitações diárias.

Estudo de Schor e Oliveira (2011) reconhecendo a concentração de população as margens do Rio Solimões-Amazonas, concluem que há um padrão diferenciado. Enquanto a rede urbana do Rio Amazonas tem infraestruturas e população que Ihes conferem densidade tecnológica e dinamismo de fluxo que se estende por toda Amazônia Oriental até fronteira marítima, incluindo Manaus e passando por Belém e Santarém, a rede urbana do Rio Solimões tem uma dinâmica mais localizada e infraestruturas mais precárias, embora mantenham importantes vínculos internacionais com Colômbia e Peru. Isso significa que a descentralização de serviços de urgência e emergência teriam investimentos e planos de implantação diferentes. Para reduzir espaço de deslocamento e custos, desenvolver polo no município de Tefé (no trecho do Rio Solimões) considerando sua localização geográfica nas proximidades da confluência de 3 importantes rios (Jutaí, Juruá e Solimões) e centro geográfico do estado e da Amazônia Internacional, além de já exercer importante papel dinamizador econômico e social de toda aquela região (QUEIROZ, 2015; RODRIGUES, 2011). Outro centro seria Parintins (no trecho Rio Amazonas), considerando ser a segunda região mais populosa no Amazonas (250 mil habitantes) e sua vocação como ponto dinamizador da região do Baixo Amazonas, incluindo parte do oeste paraense, além de já possuir certa densidade tecnológica sanitária instalada e infraestrutura.

Segundo discussões internas da Secretaria Estadual de Saúde do Amazonas, a alocação de recursos para estrutura e equipamentos na consolidação desses polos descentralizados de alta densidade tecnológica é viável, contudo o principal constrangimento seria de fato quantitativo adequado de profissionais, principalmente das especialidades médicas. Schweickardt et al (2016) apontam que a 
formação de profissionais médicos é e, com o atual modelo de formação de profissionais de saúde, continuará sendo nos próximos anos uma das maiores fragilidades para saúde no Amazonas.

Essas ideias não são novas nos círculos de discussões acadêmicas ou da gestão local, mas a explicitação dos motivos e argumentos pelos quais as normativas nacionais encontram tanta dificuldade para ser implantada no estado não tem adentrado no diálogo e das produções acadêmicas. Está claro que essas alternativas requerem estudos detalhados de viabilidade operacional e econômica, mas a intenção aqui é apontar o problema de considerar a mesma escala, quase sempre urbano centrada, e planejar o SUS universal e homogeneamente em todo território brasileiro.

\section{CONCLUSÃO}

A pergunta título deste trabalho não tem uma resposta definitiva, se não ponderada. As questões aqui apresentadas que fundamentam a regionalização tal qual instituída normativamente foram pontos relevantes e sempre presentes nos encontros coordenados pela Secretaria Estadual de Saúde do Amazonas ao debater desafios da regionalização e novo desenho das regiões de saúde para o estado. A economia de escala é um critério importante e racional como princípio para assegurar eficiência econômica do sistema, não se trata de desprezá-la ou desvaloriza-la. Mas é preciso em primeiro lugar explicita-la como estruturante no modelo de regionalização adotada no país e em segundo lugar problematiza-la como solução inequívoca aplicável em todos os lugares. O texto apresentou, contudo, que a eficiência deste princípio pressupõe a existência de uma demanda pelo serviço. Isso quer dizer que não seria oportuna em lugares do país com baixa densidade demográfica. Na prática, mesmo as regiões formalmente constituídas de fato não conseguem reduzir gastos sem redução de serviços, porque poucos são os municípios do Amazonas que compartilham serviços entre si. Manaus permanece sendo o ponto central da rede, cabendo a Secretaria Estadual de Saúde a gestão da assistência especializada e mesmo urgência.

A região amazônica não se submete a um plano de desenvolvimento e um manejo único em toda sua extensão territorial por haver distinção nas características naturais e no padrão de ocupação e uso do território (AB'SÁBER, 2004; BECKER, 2007). Este trabalho evidenciou que a população do Estado do Amazonas estabelece-se a margens dos rios, portanto parece razoável prever que alternativas no planejamento das ações públicas, incluindo os serviços de saúde, devem considerar tal fato e mais ainda, compreender que a sazonalidade no ciclo das águas nas terras de várzea molda de modo peculiar o uso do território.

Considerando que o adensamento populacional em centros urbanos é uma alternativa pouco provável e/ou desejada para resolver a questão do acesso à saúde, igualmente organizar o serviço a partir de uma lógica que centraliza atenção em pontos fixos de assistência planejados a partir de uma base populacional sem considerar sua distribuição na extensão territorial ou ainda sob critério exclusivamente econômico, tem levantado muita desconfiança nos gestores locais sobre a exequibilidade de implantar regiões de saúde como solução para responder as demandas do Estado do Amazonas. Das alternativas que vem sendo discutidas, algumas aqui apresentadas, destaca-se a ideia da mobilidade dos serviços (incluindo os profissionais) e desconcentração dos serviços da capital com o desenvolvimento de novos polos, mas não necessariamente sob os critérios que fazem algum sentido em territórios urbanos superpopulosos. Os pressupostos que orientam a organização do SUS são pensados a partir do espaço urbano e com fluxos que se dão por via terrestre, a ocupação territorial no Amazonas desafia essa racionalidade, uma vez que o rio molda o uso do território. A lógica do planejamento deve-se dar a partir dos fluxos já existentes mais do que a criação de novos pontos fixos na assistência. Em outras palavras, criar um serviço para o território e não territórios para responder ao sistema.

É essencial considerar que as relações sociais que se expressam nos territórios são resultados de jogos de poder internos e externos a eles e isso marca a implantação do SUS de formas distintas pelo país. Necessário estar atento para que por detrás de um consenso - que em política pública se expressa na forma de leis, decretos, diretrizes - não prevaleça uma postura autoritária que invisibiliza os lugares, ignorando suas formações históricas, análises dos gestores locais e o poder de inovação dos trabalhadores na construção de alternativas. Embora a regionalização seja uma estratégia para organizar mais localmente o SUS, ressalta-se que o território usado não é passível de normatizações engessadas porque é dinâmico, é um território-processo (SANTOS, 1999). Para garantir o direito 
universal à saúde, o SUS precisa ter uma organização local sem a lente de um tempo linear que desconsidera as características naturais, histórica e social dos territórios. Com frequência os estudos que pretendem analisar o Sistema a partir do grau de implementação de suas diretrizes, caem na armadilha de que há uma forma única de desenvolvimento do SUS. Nessas pretensas escalas e tipologias, historicamente o Estado do Amazonas é classificado como "atrasado" ou de "implantação tardia", interpretações que na prática pouco tem contribuído para apontar soluções apropriadas e a ultrapassar as iniquidades, porque não dão conta de revelar os reais motivos que levam a tal cenário.

Apesar de coerente o argumento político de que a regionalização pressupõe a diversidade dos lugares no território brasileiro, destaca-se que como qualquer estratégia ela é definida na pequena escala. Defendemos aqui que dada a heterogeneidade em tamanha extensão territorial, no Amazonas é preciso aumentar a escala para melhor análise e ações alternativas possíveis, dado que "a grande escala é local, detalhada, pormenorizada, próxima dos fatos e sensíveis às emoções pessoais" (SEVALHO; STOTZ, 2012, p. 905).

Os argumentos que vem sendo debatidos no nível local apontam para um tensionamento entre alguns pressupostos que orientam a regionalização, discutimos apenas dois deles, e sua efetividade em responder aquilo que são os desafios para expansão e consolidação do SUS no Amazonas. Defendemos que de partida seja adotado um discurso que não reforce esse espaço como lugar de doenças e vulnerabilidades, tornando ausente $o$ tanto de alternativas propostas e executadas pelos atores locais.

\section{REFERÊNCIAS BIBLIOGRÁFICAS}

AB'SÁBER, A. N. Amazônia: do discurso a práxis. 2a. ed. São Paulo: Edusp, 2004.

AMAZONAS. Plano Estadual de Controle, Avaliação, Regulação e Auditoria do Estado do Amazonas. Manaus: Secretaria Estadual de Saúde, 2003.

AMAZONAS. Constituição Estadual (1989). Constituição do Estado do Amazonas. Manaus, AM: Assembleia Legislativa, 2018, 139 p. 2018.

BECKER, B. K. A Amazônia e a política ambiental brasileira. In: SANTOS, M. et al (Org). Território, territórios ensaios sobre o ordenamento territorial. Rio de Janeiro: Lamparina, 2007. p. 21-40.

BRASIL. ANTAQ. Caracterização da Oferta e da Demanda do Transporte Fluvial de Passageiros e Cargas na Região Amazônica. Belém: Agência Nacional de Transportes Aquaviários, 2018. Disponível em: <http://portal.antaq.gov.br/wp-content/uploads/2018/02/produto-v.pdf>. Acesso em: 23 jan. 2019.

IBGE. Sistema IBGE de Recuperação Automática - SIDRA. Banco de tabelas estatísticas. Disponível em: <https://sidra.ibge.gov.br>. Acesso em: 25 fev. 2019.

JESUS, S. R. P. DE. Análise de competitividade dos custos logísticos do modal aéreo: estudo no setor produtor de relógios do PIM. Dissertação (Mestrado em Contabilidade e Controladoria). Manaus: Universidade Federal do Amazonas, 2014.

KADRI, M. R.; LIMA, R. T.; SCHWEICKARDT, J. C. Território e Políticas de Saúde na Amazônia: Diálogo Necessário. Seminário Internacional de Determinantes Sociais da Saúde (no prelo). Anais...Manaus: 2017

LIMA, L. D. et al. Descentralização e regionalização: dinâmica e condicionantes da implantação do Pacto pela Saúde no Brasil. Ciência \& Saúde Coletiva, v. 17, n. 7, p. 1903-1914, 2012a. ttps://doi.org/10.1590/S1413-81232012000700030

LIMA, L. D. et al. Regionalização da Saúde no Brasil. In: GIOVANELLA, L. et al (orgs). Políticas e sistema de saúde no Brasil. 2a ed. rev. e ampliada ed. Rio de Janeiro: Fiocruz/Cebes, 2012b. p. 823-852.

MENDES, E. V. As Redes de Atenção à Saúde. Brasília: Organização Pan-Americana da Saúde, 2011. 
MINISTÉRIO DA SAÚDE. Critérios e Parâmetros Assistenciais para o Planejamento e Programação de Ações e Serviços de Saúde no âmbito do Sistema Único de Saúde. Brasília: Ministério da Saúde, 2017.

MINISTÉRIO DO MEIO AMBIENTE. Caderno da Região Hidrográfica Amazônica. Brasília: MMA, 2006.

MOURA, J. B.; FROTA, C. D. Transporte misto de cargas e passageiros através de barcos regionais (recreios) no Estado do Amazonas: Uma proposta para cálculo da modicidade da tarifa. Revista Eletrônica Ciência e Desenvolvimento, v. 2, n. 3, p. 23-41, 2016.

QUEIROZ, K. O. DE. Centralidade periférica e integração relativizada: uma leitura de Tefé no Amazonas. Doutorado em Geografia Humana-São Paulo: Universidade de São Paulo, 2015.

RODRIGUES, E. A. Rede urbana do Amazonas: Tefé como cidade média de responsabilidade territorial na calha do Médio Solimões. Dissertação (Mestrado em Geografia). Manaus: Universidade Federal do Amazonas, 2011.

SANTANA, P. Introdução à geografia da saúde território, saúde e bem-estar. 1a. ed. Coimbra, Portugal: Imprensa da Universidade de Coimbra, 2014. https://doi.org/10.14195/978-989-26-0727-6

SANTOS, M. Território e o saber local: algumas categorias de análise. Cadernos IPPUR, v. 2, p. 1525, 1999

SCHOR, T.; OLIVEIRA, J. A. Reflexões metodológicas sobre o estudo da rede urbana no Amazonas e perspectivas para a análise das cidades na Amazônia brasileira. Revista ACTA Geográfica, p. 1530, 2011. https://doi.org/10.5654/actageo2011.0001.0001

SCHWEICKARDT, J. C. et al. Cenário da Gestão do Trabalho no Amazonas: fixação e provimento de profissionais de saúde no SUS. (Relatório de Pesquisa). Manaus: Instituto Leônidas e Maria Deane - ILMD/Fiocruz Amazônia, 2016.

SCHWEICKARDT, J. C.; MARTINS, L. R. História das Políticas de Saúde no Amazonas: da Zona Franca ao SUS, 1967-1990. In: SCHWEICKARDT, J. C. et al. (Orgs). História e Política de Saúde na Amazônia. Saúde e Amazônia. 1. ed. Porto Alegre: Rede Unida, 2017.

SEVALHO, G.; STOTZ, E. A cartografia simbólica do risco epidemiológico: uma incursão ao pensamento de Boaventura de Sousa Santos. História, Ciências, Saúde-Manguinhos, v. 19, n. 3, p. 899-918, 2012. https://doi.org/10.1590/S0104-59702012000300007

VIANA, A. L. D'ÁVILA; LIMA, L. D. DE; FERREIRA, M. P. Condicionantes estruturais da regionalização na saúde: tipologia dos Colegiados de Gestão Regional. Ciência \& Saúde Coletiva, v. 15, n. 5, p. 2317-2326, 2010. https://doi.org/10.1590/S1413-81232010000500007

VICTORA, C. G. et al. Health conditions and health-policy innovations in Brazil: the way forward. The Lancet, v. 377, n. 9782, p. 2042-2053, jun. 2011. https://doi.org/10.1016/S0140-6736(11)60055-X 